\title{
Off-pump implantation of the HeartMate 3 left ventricular assist device through a bilateral thoracotomy approach
}

\author{
Evgenij V. Potapov, MD, PhD, ${ }^{\mathrm{a}, \mathrm{b}}$ Marian Kukucka, MD, PhD, ${ }^{\mathrm{a}}$ Volkmar Falk, MD, PhD, ${ }^{\mathrm{a}, \mathrm{b}, \mathrm{c}}$ and \\ Thomas Krabatsch, MD, PhD, ${ }^{\mathrm{a}, \mathrm{b}}$ Berlin, Germany
}

From the ${ }^{\mathrm{a}}$ Deutsches Herzzentrum Berlin; the ${ }^{\mathrm{b}}$ DZHK (German Centre for Cardiovascular Research), Partner Site Berlin; and the ${ }^{\mathrm{c}}$ Department of Cardiovascular Surgery, Charité-Universitätsmedizin Berlin, Berlin, Germany. The costs of video production were covered by an educational grant from St Jude Medical, owner of Thoratec. The case presented was not part of a CE Mark trial.

Disclosures: Volkmar Falk reports consulting fees from Philips, Heartware, Berlin heart, Aesculap, and Thoratec; speaker fees from Medtronic, Edwards, St. Jude Medical, and Aesculap; and research funding from Philips, Valtech, Medtronic, Biotronik, and Boston Scientific. All other authors have nothing to disclose with regard to commercial support

Received for publication June 30, 2016; revisions received Aug 25, 2016; accepted for publication Sept 5, 2016; available ahead of print Oct 14, 2016

Address for reprints: Evgenij V. Potapov, MD, PhD, Department of Cardiothoracic and Vascular Surgery, Deutsches Herzzentrum Berlin, Augustenburger Platz 1, 13353 Berlin, Germany (E-mail: Potapov@ dhzb.de). J Thorac Cardiovasc Surg 2017;153:104-5

$0022-5223 / \$ 36.00$

Copyright (C) 2016 by The American Association for Thoracic Surgery

http://dx.doi.org/10.1016/j.jtcvs.2016.09.028

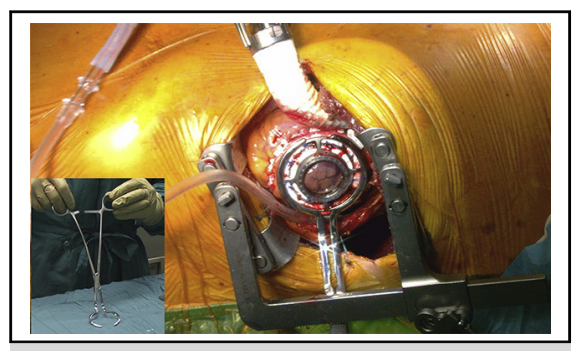

Clamp for holding the fixation ring during off pump insertion of the inflow cannula.

Central Message

This technique avoids sternotomy and allows a low heparin dose, with subsequent reduced risk of bleeding. The short operating time and an intact sternum may lead to faster recovery.

See Editorial Commentary page 106.
The implantation of left ventricular assist devices without sternotomy is increasingly gaining interest among surgeons because of its many advantages: fewer sternal adhesions, postulated preservation of right ventricular function by prevention of distention, less bleeding, and faster recovery. ${ }^{1-3}$ The approach gained significant acceptance after the introduction of the miniaturized intrapericardially placed HeartWare HVAD (HeartWare, Framingham, Mass). At our institution we prefer the bilateral thoracotomy approach carried out with miniaturized cardiopulmonary bypass in standby. ${ }^{4}$ The HeartMate 3 device (Thoratec Corporation, Pleasanton, Calif), recently introduced into clinical practice and commercially available in Europe, is also implanted with this technique at our institution.

\section{SURGICAL TECHNIQUE}

The surgical approach is presented in Video 1. Briefly, the implantation procedure is carried out by 2 surgeons working in concert. Guidewires are placed into groin vessels to facilitate rapid installation of cardiopulmonary bypass in the case of emergency. One surgeon attaches the fixation ring to the apex through the fifth or sixth left intercostal space, while the second measures the required length of the graft, cuts it, and performs the anastomosis to the lateral side of the ascending aorta through the third right intercostal space. The graft should lie on the right ventricle close to the diaphragm, then between the right atrium and pericardium, crossing the atrium over the very distal part of the superior vena cava and connected to the ascending aorta. Because the graft increases in length under pressure, measurement of the optimal length may be performed in two ways. First, the shortest distance

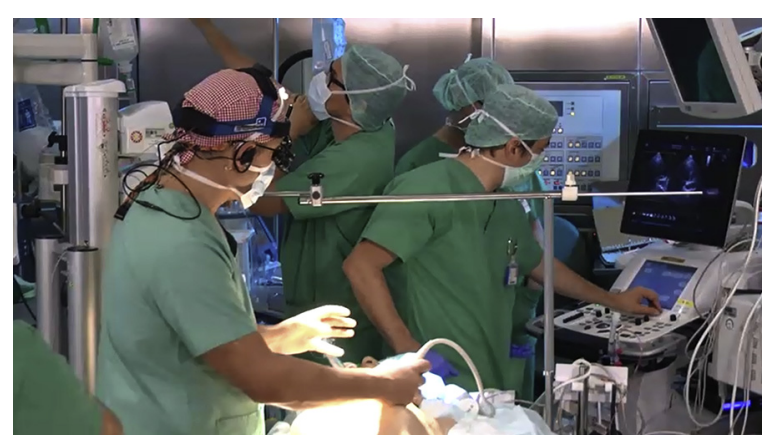

VIDEO 1. The video demonstrates the implantation of a HeartMate 3 (Thoratec Corporation, Pleasanton, Calif) left ventricular assist device without sternotomy in an off-pump technique, performed by 2 surgeons working in concert. A special clamp is seen that was developed to hold the heart in the appropriate position throughout the procedure, especially if the heart becomes empty after coring and ejection of the blood and the bulky pump obstructs the view into the operating field. The clamp is closed around the fixation ring attached to the heart and holds it in the correct position, facilitating closure of the fixation mechanism. Video available at: http://www. jtcvsonline.org/article/S0022-5223(16)31146-1/addons. 


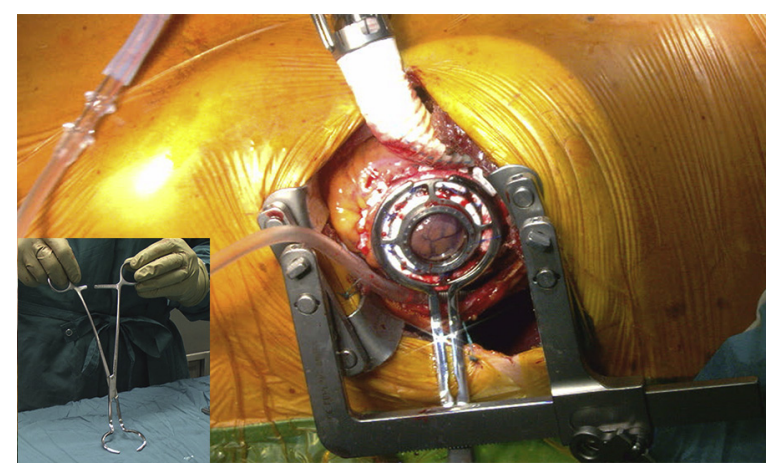

FIGURE 1. Special clamp developed to hold the heart in the appropriate position throughout the implantation of the HeartMate 3 (Thoratec Corporation, Pleasanton, Calif) left ventricular assist device.

between the fixation ring and the further aortic anastomosis is measured by a simple suturing thread passed intrapericardially with the required length measured in "nonpressurized status." Second, the graft is stretched or pressurized with saline solution, and the "real length" is measured by laying the graft outside of the chest in the manner described previously and shown in Video 1 (at time 1:38). After completion of the anastomosis, the partial aortic clamp remains closed, and the graft is still free of blood. The graft and kinking protector are connected to the pump. After administration of 5000 IU heparin and the start of rapid pacing, the left ventricle is cored and the inflow cannula of the pump is inserted during continuous retrograde deairing by release of the partial aortic clamp. The HeartMate 3 pump should have full contact to the fixation ring to release the fixation mechanism. To hold the heart in the appropriate position throughout the incision on the left side, especially if the heart becomes empty and shrinks into pericardium after coring and ejection of the blood and the bulky pump obstructs the view into the operating field, we developed a special clamp (Fittkau Metallbau GmbH, Berlin, Germany), which can be seen in Video 1 and is now commercially available. This clamp is closed around the fixation ring attached to the heart and holds it in the correct position, facilitating closure of the fixation mechanism (Figure 1). After the pump is secured in the ring, it is immediately started. Protamine is administered and the chest is closed. The final positioning of the pump and the outflow graft is shown in Figure 2.

The HeartMate 3 pump diameter is $50.5 \mathrm{~mm}$; if the metal outflow part and the cable exit are included, however, the diameter increases to $74.5 \mathrm{~mm}$. In addition, the rigid metal outflow and the large kinking protector complicate the handling of the pump. Use of the specially designed clamp allows insertion of the HeartMate 3 pump in a technique similar to that previously described for the HeartWare HVAD through a small intercostal incision.

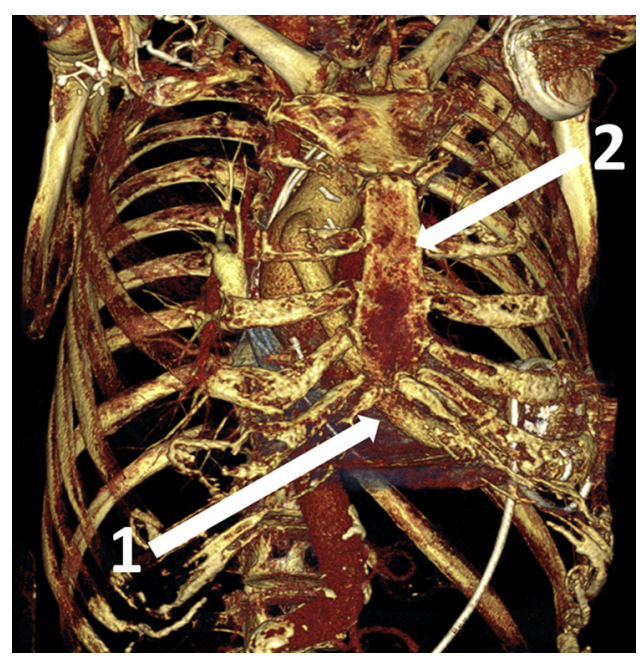

FIGURE 2. Reconstruction of the computed tomographic scan shows the final graft position. Arrows indicate the optimal position of the outflow graft placed intrapericardially (1) and the intact sternum (2).

\section{DISCUSSION}

The presented technique has multiple advantages. First, it completely avoids sternotomy and later adhesions behind the sternum. Second, during off-pump implantation, keeping the partial aortic clamp closed until deairing and pump start allows a low heparin dose and thus reduced risk of bleeding. Third, the short operating time and an intact sternum may lead to faster recovery. The effectiveness of the HeartMate 3 compared to other left ventricular assist devices, however, is yet to be determined. The potential risks of the approach may be limited exposure of the apex if bleeding occurs and the fact that unexpected adhesions may necessitate conversion to the standard sternotomy approach. The described technique is suitable for patients with good right ventricular function and without the need for concomitant procedures. In the case of a reoperative procedure, we recommend the left lateral approach with connection of the outflow graft to the descending aorta. ${ }^{6}$

\section{References}

1. Cheung A, Soon JL, Bashir J, Kaan A, Ignaszewski A. Minimal-access left ventricular assist device implantation. Innovations (Phila). 2014;9: 281-5.

2. Haberl T, Riebandt J, Mahr S, Laufer G, Rajek A, Schima H, et al. Viennese approach to minimize the invasiveness of ventricular assist device implantation. Eur J Cardiothorac Surg. 2014;46:991-6; discussion 996.

3. Strueber M, Meyer AL, Feussner M, Ender J, Correia JC, Mohr FW. A minimally invasive off-pump implantation technique for continuous-flow left ventricular assist devices: early experience. J Heart Lung Transplant. 2014;33: 851-6.

4. Potapov EV, Krabatsch T. Minimally invasive continuous-flow left ventricular assist device implantation: avoiding a median sternotomy. J Heart Lung Trans plant. 2014;33:1199-200.

5. Netuka I, Sood P, Pya Y, Zimpfer D, Krabatsch T, Garbade J, et al. Fully magnetically levitated left ventricular assist system for treating advanced HF: a multicenter study. J Am Coll Cardiol. 2015;66:2579-89.

6. Schulz A, Stepanenko A, Krabatsch T. HeartMate 3 implantation via left lateral thoracotomy with outflow graft anastomosis to the descending aorta. J Heart Lung Transplant. 2016;35:690-2. 